\title{
UPAYA PENINGKATAN KEMAMPUAN BERBAHASA INGGRIS MELALUI PROGRAM STUDY VISIT KE LUAR NEGERI
}

\author{
Muhfizaturrahmah $^{1}$, Yulieda Hermaniar ${ }^{2}$, Nurhening Yuniarti ${ }^{1}$ \\ ${ }^{1}$ Jurusan Pendidikan Teknik Elektro FT UNY; ${ }^{2}$ Jurusan Pendidikan Bahasa Inggris STKIP Banjarmasin \\ Email: muhfizaturrahmah@uny.ac.id
}

\begin{abstract}
This paper depicts the efforts done in order to improve undergraduate of Didactic of Electrical Engineering students' English competence through series of activities on international study visit (SV) program. The study visit program was done in Germany in which students actively engage with activities conducted using English as international language in four main English competence standard: reading, listening, speaking and writing. This paper is a descriptive study which its data collecting method was done by observation and interview. Both photos and videos were taken as secondary data. The result of the study is presented under the discussion of participants' responses toward the program as well as the program impact toward their learning attitudes.
\end{abstract}

Keywords: English competence, study visit, didactic of electrical engineering

\begin{abstract}
ABSTRAK
Penelitian ini merupakan tulisan mengenai upaya-upaya yang dilakukan sebagai langkah meningkatkan kemampuan berbahasa inggris mahasiswa program sarjana di Jurusan Pendidikan Teknik Elektro melalui serangkaian aktivitas pada program study visit (SV). Program ini dilaksanakan di Jerman dimana mahasiswa terlibat aktif menggunakan bahasa inggris yang meliputi aspek membaca, mendengar, berbicara dan menulis. Penelitian ini menggunakan pendekatan deskriptif dimana gambaran mengenai proses perancangan aktivitas program dan pelaksanaan kegiatan SV dijabarkan secara mendetail. Pengumpulan data dilakukan melalui pengamatan dan wawancara. Foto dan video juga diambil sebagai data sekunder. Hasil dari kajian ini disajikan dalam diskusi terkait respon peserta terhadap program dan pengaruh program terhadap perilaku belajar peserta.
\end{abstract}

Kata kunci: kemampuan berbahasa inggris, study visit, pendidikan teknik elektro

\section{PENDAHULUAN}

Tidak dapat dielak bahwa kemampuan berbahasa inggris yang mumpuni mengantar pada terbukanya lebih banyak kesempatan untuk bekerja khususnya di perusahaan multinational di era Mayarakat Ekonomi ASEAN (MEA) saat ini (Aruminta, 2015: 1118). Namun, sebagian besar mahasiswa teknik masih enggan menggunakan bahasa inggris dalam kehidupan sehari-hari. Padahal mahasiswa bidang teknik sangat membutuhkan penguasaan bahasa inggris khususnya kemampuan membaca (reading) dan berbicara (speaking) (Gözüyeşil, 2014: 4182- 4186). Hal ini disebabkan antara lain karena tidak terbangunnya kebiasaan menggunakan bahasa inggris sebagai bahasa kedua, khawatir akan dianggap arogan, dan keyakinan yang salah bahwa bahasa inggris itu sulit dan tidak semua orang memiliki kecerdasan linguistik yang tinggi.

Menyikapi kendala dalam peningkatan kemampuan berbahasa inggris yang dihadapi mahasiswa, Jurusan Pendidikan Elektro, Fakultas Teknik Universitas Negeri Yogyakarta (FT UNY), sejak 2014 dengan aktif melaksanakan kegiatan internasionalisasi program studi yang programnya didominasi oleh kegiatan peningkatan berbahasa inggris seperti English Club, Focus Group Discussion, dan Bi-lingual Class (Yuniarti, 2015). Selain 
itu, FT UNY juga mengirim dosen-dosen muda untuk belajar bahasa inggris intensif selama tiga bulan di lembaga bahasa agar kemampuan para pengajar dalam mengelola kelas dalam bahasa inggris meningkat.

Pengelolaan kelas yang menarik tidak terlepas dari pembuatan rancangan pembelajaran yang matang dan terstruktur dengan baik. Persiapan guru mencakup materi pembelajaran, media, maupun pemilihan teknik pengajaran yang inovatif menjadikan pembelajaran bahasa menjadi efektif. Namun perlu disadari bahwa pengajaran bahasa berkaitan dengan proses pemerolehan bahasa yang berasal dari lingkungan. Seperti diketahui bersama, bahasa inggris di Indonesia kedudukannya masih merupakan bahasa asing sehingga paparan yang didapatkan siswa untuk berbahasa inggris masih cenderung rendah. Seperti yang dikemukakan Hermaniar (Hermaniar, 2016: 81-90) bahwa kedudukan bahasa inggris sebagai bahasa asing menyebabkan siswa memiliki kemampuan yang kurang dalam kemampuan berbicara bahasa inggris karena bahasa inggris bukan bahasa sehari-hari. Oleh karena itu, pembelajaran bahasa inggris perlu membentuk suatu lingkungan dengan paparan bahasa yang tinggi dengan cara membentuk komunitas berbicara bahasa inggris (English club) ataupun study visit.

Study visit merupakan program dimana siswa menghabiskan kurun waktu tertentu di suatu negara untuk mempelajari sesuatu. Dalam proses belajar tersebut melibatkan interaksi sosial yang natural serta melibatkan proses berbahasa inggris. Selama proses study visit, siswa dihadapkan dengan kondisi dimana penggunaan bahasa inggris bersifat keharusan sehingga mendorong mereka untuk menggunakan bahasa inggris dengan tujuan komunikatif. Selain itu, selama study visit siswa juga menyediakan ruang yang cukup untuk mengeksplorasi kemampuan berbahasa mereka dalam situasi yang sebenarnya. Kondisi seperti ini tidak ditemui di dalam pembelajaran di dalam kelas lokal dimana mereka masih memiliki pilihan untuk tidak menggunakan bahasa inggris secara menyeluruh.

Study visit sendiri merupakan program yang tidak mudah dilaksanakan karena melibatkan proses panjang dari segi perencanaan, pelaksanaan, serta pelaporan. Oleh karena itu, penelitian kualitatif terkait upaya-upaya yang dilakukan sebagai langkah meningkatkan kemampuan berbahasa inggris mahasiswa program sarjana di Jurusan Pendidikan Teknik Elektro melalui serangkaian aktivitas pada program study visit dirasa menarik dan relevan untuk dipelajari.

\section{METODE}

Penelitian ini adalah penelitian kualitatif deskriptif. Empat belas orang mahasiswa program sarjana di Jurusan Pendidikan Teknik Elektro, Fakultas Teknik, Universitas Negeri Yogyakarta dengan tingkat penguasaan bahasa inggris bervariasi, skor TOELF-Like antara 430-593, dilibatkan sebagai subjek dalam penelitian ini. Subjek merupakan mahasiswa Program Studi Pendidikan Teknik Elektro dan Pendidikan Teknik Mekatronika yang sedang menempuh perkuliahan tahun kedua (3 orang), tahun ketiga ( 3 orang), dan tahun keempat ( 8 orang).

Pengambilan data dilakukan dengan melakukan pengamatan yang mengacu pada lembar observasi saat proses seleksi, pengajuan usulan program, persiapan keberangkatan, dan pelaksanaan program. Wawancara dilakukan selama program berlangsung terhadap 14 mahasiswa. In-depth interview juga dilakukan terhadap lima orang mahasiswa setelah program selesai dilaksanakan. Sebagai data pendukung, foto dan video diambil selama program study visit dilaksanakan.

Data hasil pengamatan dianalisis dengan menggunakan model penyederhanaan sebagaimana yang dilakukan Hermaniar (Hermaniar, 2016: 81-90) yang merujuk pada metode analasis data deskriptif kualitatif oleh Sukardi (2006) yang ditampilkaan pada alur Gambar 1. 


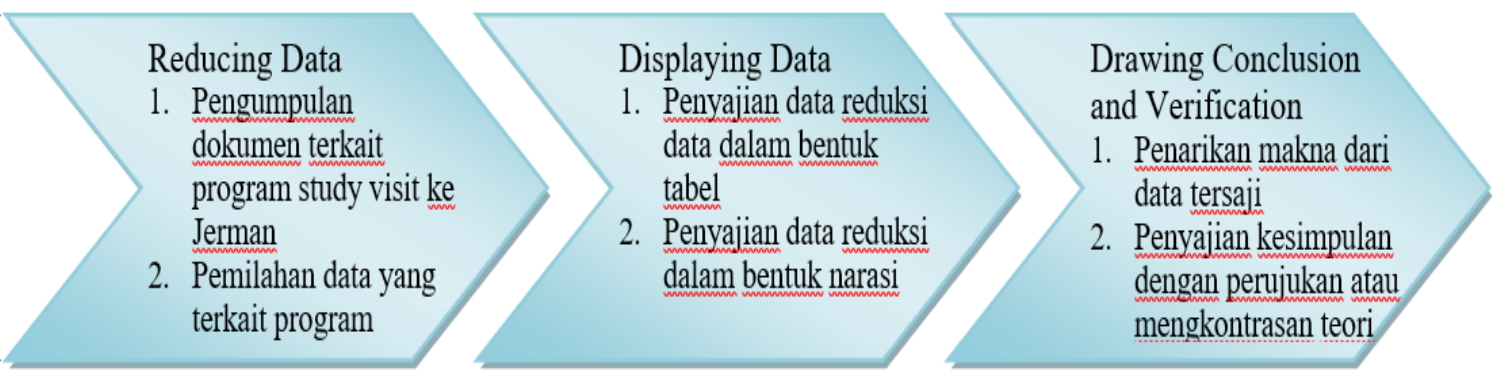

Gambar 1. Metode Analasis Data Deskriptif Kualitatif

\section{HASIL DAN PEMBAHASAN}

Empat belas orang mahasiswa program sarjana di Jurusan Pendidikan Teknik Elektro, Universitas Negeri Yogyakarta mengikuti kegiatan study visit ke Jerman dimana mereka terlibat secara total dalam perencanaan, pelaksanaan dan pasca kegiatan. Persiapan program dimulai dengan seleksi mahasiswa peserta study visit yang berlangsung dalam dua tahap wawancara di bulan maret hingga april 2017. Setelah peserta SV terpilih, tim dibagi menjadi 5 tim kecil yang menangani tugas dengan fokus tertentu yaitu tim perancang jadwal kegiatan, tim perumus proposal kegiatan, tim penyusun profil peserta SV, tim komunikasi dengan institusi partner dan tim teknis pendukung. Pembagian tim kecil ini adalah untuk memastikan bahwa semua peserta berperak aktif dalam persiapan program SV.

Salah satu peran peserta yang ingin ditekankan dalam kegiatan SV adalah keikutsertaannya dalam menggunakan bahasa inggris produktif (speaking dan writing). Kegiatan persiapan ditampilkan dalam Tabel 1.

Koordinasi dilakukan rutin perbulan untuk meninjau progres dokumen pengajuan pendanaan yang mana seluruhnya ditulis dalam bahasa inggris. Dokumen tersebut terdiri dari Project Description, Statement of Motivation and Description of Program Content, Schedule, Description of Content Preparation, Proof of Contacts, Financial Plan, and Profile of Participants. Berikut adalah langkah-langkah yang ditempuh oleh dosen pendamping kegiatan dalam meningkatkan kemampuan bahasa inggris mahasiswa peserta study visit:

1. Koordinasi Rutin

Pertemuan rutin dilakukan pada minggu I dan III setiap bulan dengan tujuan melakukan koordinasi dan berbagi pengetahuan tentang negara Jerman, sejarah Jerman, tempat-tempat yang menjadi daya tarik Jerman. Mahasiswa peserta SV secara bergantian melakukan presentasi yang disiapkan sepanjang maksimal 10 slide presentasi dan disampaikan dalam bahasa inggris selama kurang lebih 30 menit. Kemampuan berkomunikasi secara efektik dan efisien dengan bahasa yang santun dilatih di forum ini. Sesi diskusi dan tanya jawab ditekankan untuk memberi umpan balik presentasi sehingga ditemukan saran dan kritik yang membangun untuk presentasi selanjutnya.

2. Whatsapp grup

Obrolan via grup Whatsapp (WA) dimulai sejak wal terbentuknya tim pada maret 2017. Selama 14 bulan sejak tim SV dibentuk hingga program SV selesai, diskusi kerap dilakukan melalui media ini, Hal tersebut ditujukan agar mahasiswa semakin terbiasa menggunakan percakapan harian hanya dalam bahasa inggris. Setiap penggunaan bahasa selain bahasa inggris 
dicatat sebagai pelanggaran grup dan diberikan sangsi.

3. Pembekalan Budaya dan Bahasa

Bahasa tidak akan pernah terpisah dari budaya suatu bangsa. Sebelum mahasiswa dibekali bahasa Jerman sebagai bahasa ibu para penduduk Jerman, mahasiswa juga dibekali budaya Jerman. Pembekalan budaya dilakukan dua kali yakni saat tim SV awal terbentuk dan tiga bulan sebelum keberangkatan oleh pemateri yang pernah kuliah dan bekerja di Jerman. Porsi pembekalan budaya yang diberikan dilengkapi dengan budaya negara Singapura dan Uni Emirat Arab mengingat dua negara tersebut juga akan dikunjungi saat proses transit. Kemampuan berkomunikasi lisan dengan sopan dengan berpedoman pada budaya negera setempat ditekankan pada pembekalan ini.

4. Penulisan Artikel
Salah satu tugas yang harus dilakukan mahasiswa peserta SV adalah membuat tulisan pendek dalam bahasa inggris dengan tema How Technology Supports Library Users in Self-Learning? Mahasiswa mengamati teknologi yang menunjang proses belajar pada salah satu perpustakaan terbesar di Jerman. Tugas ini berpedoman pada IELTS Writing Task 2 yaitu diperlukan minimal 250 kata dengan menekankan faktor koherensi dan grammar sebagai language focus.

Program Study Visit yang berlangsung 14 hari ini dilaksanakan sebagian besar di Jerman, yaitu di kota Dresden, Freiberg dan Berlin. Selebihnya, kota Abu Dabi, Uni Emirat Arab dan Singapura juga disinggahi sebagai kota transit dalam perjalanan SV. Detail kegiatan SV dijabarkan pada Tabel 2.

Tabel 1. Kegiatan Persiapan Study Visit Luar Negeri Jurusan Pendidikan Teknik Elektro UNY

\begin{tabular}{|l|c|l|l|}
\hline No & $\begin{array}{c}\text { Jumlah } \\
\text { Pertemuan }\end{array}$ & \multicolumn{1}{|c|}{ Aktivitas } & \multicolumn{1}{|c|}{ Pelaksanaaan } \\
\hline 1 & 12 & Koordinasi Rutin & Minggu I tiap bulan \\
\hline 2 & 2 & Pembekalan Budaya & April 2017, Januari 2018 \\
\hline 3 & 12 & Pembekalan Bahasa & Minggu II tiap bulan \\
\hline 4 & 12 & Latihan Presentasi & Minggu III tiap bulan \\
\hline
\end{tabular}


Tabel 2. Aktifitas Kegiatan Program Study Visit

\begin{tabular}{|c|c|c|c|c|}
\hline Day & Date & Time & Activities & Host/Location \\
\hline 1 & $\begin{array}{l}\text { Sunday, } \\
\text { April } \\
8 \text { th, } \\
2018\end{array}$ & $07: 25$ & Departure & Adi Sucipto Airport, Yogyakarta \\
\hline \multirow[t]{3}{*}{2} & \multirow{3}{*}{$\begin{array}{l}\text { Monday, } \\
\text { April } \\
9 \text { th, } \\
2018\end{array}$} & 06.45 & Arrival & $\begin{array}{l}\text { Frankfurt am Main Airport, } \\
\text { Frankfurt, Germany }\end{array}$ \\
\hline & & $\begin{array}{l}15.20- \\
19: 36\end{array}$ & Frankfurt - Dresden & By Train \\
\hline & & 22.00 & Check in & $\begin{array}{l}\text { Pension Am Kirschberg } \\
\text { Address: Nöthnitzer Hang 27, } \\
01728 \text { Bannewitz, Germany }\end{array}$ \\
\hline \multirow[t]{5}{*}{3} & \multirow[t]{5}{*}{$\begin{array}{l}\text { Tuesday, } \\
\text { April } \\
10 \text { th, } \\
2018\end{array}$} & $\begin{array}{l}08.30- \\
10.30\end{array}$ & $\begin{array}{l}\text { Generale Studium } \\
\text { Cutting Edge Vocational } \\
\text { Education Technology in } \\
\text { Germany }\end{array}$ & $\begin{array}{l}\text { Prof. Dr. phil. habil. Martin } \\
\text { Hartmann } \\
\text { Chair of Metals and Machine } \\
\text { Technology, Vocational Didactics } \\
\text { Institute for Vocational Education } \\
\text { and Didactis, TU Dresden }\end{array}$ \\
\hline & & $10.30-12.00$ & $\begin{array}{l}\text { Presentation: } \\
\text { German Qualifications } \\
\text { Framework (GQF) } \\
\end{array}$ & $\begin{array}{l}\text { Prof. Dr. phil. habil. Martin } \\
\text { Hartmann } \\
\text { TU Dresden }\end{array}$ \\
\hline & & $12.00-13.00$ & Lunch & Mensa, TU Dresden \\
\hline & & $13.00-16.00$ & Lab Visit & $\begin{array}{l}\text { Mediencentrum TU Dresden } \\
\text { Prof. Dr. Thomas Kohler } \\
\text { Institute for Vocational Education } \\
\text { and Didactis / Educational } \\
\text { Technology Chair, TU Dresden }\end{array}$ \\
\hline & & $16.00-18.00$ & $\begin{array}{l}\text { Student Assignment } \\
\text { 250 Word Article Writing } \\
\\
\text { Topic: How Technology } \\
\text { Supports Library Users in } \\
\text { Self-Learning? }\end{array}$ & $\begin{array}{l}\text { Supervised by Ms. } \\
\text { Muhfizaturrahmah (YSU) } \\
\text { Sächsische Landesbibliothek- } \\
\text { Staatsund Universitätsbibliothek } \\
\text { Dresden (SLUB) }\end{array}$ \\
\hline \multirow[t]{3}{*}{4} & \multirow[t]{3}{*}{$\begin{array}{l}\text { Wed } \\
\text { April } \\
11 \text { th, } \\
2018\end{array}$} & $07.30-09.00$ & $\begin{array}{l}\text { Sit-In: International Class } \\
\text { Subject Matter: Media } \\
\text { Technology for Vocational } \\
\text { Education }\end{array}$ & $\begin{array}{l}\text { Faculty of Education } \\
\text { TU Dresden }\end{array}$ \\
\hline & & $09.00-10.30$ & $\begin{array}{l}\text { Discussion of Strategic } \\
\text { Research Areas and } \\
\text { Opportunities of Pursuing } \\
\text { Higher Studies }\end{array}$ & TU Dresden \\
\hline & & $10.30-12.30$ & $\begin{array}{l}\text { Focus Group Discussion } \\
\text { (FGD) of Educational } \\
\text { Technology and Media } \\
\text { Development in Indonesia } \\
\text { Topics: } \\
\text { Teaching Technology of } \\
\text { Vocational Education in }\end{array}$ & $\begin{array}{l}\text { Presenters: Ilham Wisnu Aji and } \\
\text { M. Lutfil Hakim (YSU Students) } \\
\text { Participants: YSU students and TU } \\
\text { Dresden students } \\
\text { Department of Vocational } \\
\text { Education, TU Dresden }\end{array}$ \\
\hline
\end{tabular}




\begin{tabular}{|c|c|c|c|c|}
\hline & & & $\begin{array}{l}\text { Indonesia } \\
\text { Learning Media in } \\
\text { Indonesia }\end{array}$ & \\
\hline & & $12.30-13.30$ & Lunch & Mensa, TU Dresden \\
\hline & & $13.30-15.00$ & $\begin{array}{l}\text { Comparison Study of } \\
\text { Technical Facilities at } \\
\text { University Library }\end{array}$ & $\begin{array}{l}\text { TU Dresden Volunteer Students } \\
\text { Sächsische Landesbibliothek- } \\
\text { Staatsund Universitätsbibliothek } \\
\text { Dresden (SLUB) }\end{array}$ \\
\hline & & $\begin{array}{l}15.00- \\
16.00\end{array}$ & Campus Guided Tour & TU Dresden \\
\hline 5 & $\begin{array}{l}\text { Thursda } \\
\mathrm{y}\end{array}$ & $08.30-12.00$ & $\begin{array}{l}\text { Visiting Vocational High } \\
\text { School }\end{array}$ & Organized by TU Dresden \\
\hline & April & $12.00-13.00$ & Lunch & \\
\hline & $\begin{array}{l}12 \text { th } \\
2018\end{array}$ & $13.00-16.00$ & $\begin{array}{l}\text { Visiting Faculty of } \\
\text { Electrical and Computer } \\
\text { Engineering. } \\
\text { Discussion with PhD } \\
\text { students. } \\
\text { Topic: Optimization of } \\
\text { Internet of Things (IOT) in } \\
\text { Supporting Electrical } \\
\text { Engineering Study }\end{array}$ & $\begin{array}{l}\text { Faculty of Electrical and } \\
\text { Computer Engineering } \\
\text { TU Dresden }\end{array}$ \\
\hline & & $\begin{array}{l}16.00- \\
18.00\end{array}$ & City Walking & Dresden \\
\hline 6 & $\begin{array}{l}\text { Friday } \\
\text { April } \\
13 \text { th, } \\
2018\end{array}$ & $\begin{array}{l}09.00- \\
12.00\end{array}$ & Visiting Company & $\begin{array}{l}\text { VW Manufacture } \\
\text { Lennéstraße 1, } 01069 \text { Dresden }\end{array}$ \\
\hline & & $13.00-17.00$ & $\begin{array}{l}\text { Cooking Together with } \\
\text { International Students in } \\
\text { TU Dresden }\end{array}$ & International Students' Flat \\
\hline 7 & $\begin{array}{l}\text { Saturday } \\
\text { April } \\
14 \text { th, } \\
2018\end{array}$ & $09.00-12.00$ & $\begin{array}{l}\text { Observation: Technology } \\
\text { Implementation in } \\
\text { Bridging Education and } \\
\text { Industry }\end{array}$ & $\begin{array}{l}\text { Dresden Museum of Technology } \\
\text { and Industry } \\
\text { Junghansstr. 1-3, } 01277 \text { Dresden, } \\
\text { Saxony }\end{array}$ \\
\hline & & $\begin{array}{l}12.00- \\
16.00\end{array}$ & Hunting for Souvenirs & Dresden \\
\hline 8 & $\begin{array}{l}\text { Sunday } \\
\text { April } \\
15 \text { th, }\end{array}$ & $\begin{array}{l}05.25- \\
08.10\end{array}$ & Dresden - Berlin & $\begin{array}{l}\text { By Bus } \\
\text { Dresden HBF - Berlin ZOB Am } \\
\text { Funkturm }\end{array}$ \\
\hline & 2018 & $\begin{array}{l}08.30- \\
12.00\end{array}$ & $\begin{array}{l}\text { Understanding the History } \\
\text { of Germany }\end{array}$ & $\begin{array}{l}\text { Guided by Indonesian Students } \\
\text { Alliance in Germany } \\
\text { Brandenburgertor } \\
\text { Berlin Wall } \\
\end{array}$ \\
\hline & & $\begin{array}{l}12.00- \\
13.00\end{array}$ & Lunch & \\
\hline & & $\begin{array}{l}13.00- \\
14.30\end{array}$ & City Tour & Berlin \\
\hline & & $\begin{array}{l}14.30- \\
16.30\end{array}$ & City Walking & \\
\hline
\end{tabular}




\begin{tabular}{|c|c|c|c|c|}
\hline & & $\begin{array}{l}17.00- \\
19.35\end{array}$ & Berlin - Dresden & $\begin{array}{l}\text { By Bus } \\
\text { Berlin ZOB Am Funkturm - } \\
\text { Dresden HBF }\end{array}$ \\
\hline \multirow[t]{7}{*}{9} & \multirow{7}{*}{$\begin{array}{l}\text { Monday } \\
\text { April } \\
16 \text { th, } \\
2018\end{array}$} & $\begin{array}{l}09.52- \\
10.25\end{array}$ & Dresden - Freiberg & By Train \\
\hline & & $\begin{array}{l}11.00- \\
13.00\end{array}$ & $\begin{array}{l}\text { Opening Event } \\
\text { Presentation of University }\end{array}$ & $\begin{array}{l}\text { Alte Mensa, Petersstraße 5, } \\
\text { Bergmannszimmer } \\
\text { TU Bergakademie Freiberg }\end{array}$ \\
\hline & & $\begin{array}{l}13.00- \\
14.00\end{array}$ & Informal Lunch & $\begin{array}{l}\text { Mensa, TU Bergakademie } \\
\text { Freiberg }\end{array}$ \\
\hline & & $\begin{array}{l}14.00- \\
16.30\end{array}$ & Post Graduate Studies & $\begin{array}{l}\text { Center of Advanced Study and } \\
\text { Research } \\
\text { TU Bergakademie Freiberg }\end{array}$ \\
\hline & & $\begin{array}{l}16.30- \\
18.00\end{array}$ & Visit StudE-Lab & $\begin{array}{l}\text { Department Electrical } \\
\text { Engineering, TU Bergakademie } \\
\text { Freiberg }\end{array}$ \\
\hline & & $\begin{array}{l}18.00- \\
20.00\end{array}$ & Dinner & Freiberg (Stadtwirtschaft) \\
\hline & & $\begin{array}{l}20.31- \\
21.05\end{array}$ & Freiberg - Dresden & By Train \\
\hline \multirow[t]{5}{*}{10} & \multirow{5}{*}{$\begin{array}{l}\text { Tuesday, } \\
\text { April } \\
17 \text { th, } \\
2018\end{array}$} & $\begin{array}{l}08.52- \\
09.25\end{array}$ & Dresden - Freiberg & By Train \\
\hline & & $\begin{array}{l}10.00- \\
12.00\end{array}$ & $\begin{array}{l}\text { Presentation and Workshop } \\
\text { : Digital Media in Higher } \\
\text { Education }\end{array}$ & $\begin{array}{l}\text { Yulia Dolganova and Aline } \\
\text { Bergert } \\
\text { Prüferstr. 1, 09599 Freiberg } \\
\text { TU Bergakademie Freiberg }\end{array}$ \\
\hline & & $\begin{array}{l}12.00- \\
13.00\end{array}$ & $\begin{array}{l}\text { Lunch in Cafeteria with } \\
\text { Indonesians Studying in } \\
\text { Freiberg }\end{array}$ & TU Bergakademie Freiberg \\
\hline & & $\begin{array}{l}13.30- \\
17.00\end{array}$ & Visit of Terra Mineralia & $\begin{array}{l}\text { Schlossplatz 4, Schloss } \\
\text { Freudenstein, 09599, Freiberg }\end{array}$ \\
\hline & & $\begin{array}{l}17.31- \\
18.05\end{array}$ & Freiberg - Dresden & By Train \\
\hline \multirow[t]{7}{*}{11} & \multirow{7}{*}{$\begin{array}{l}\text { Wed } \\
\text { April } \\
18 \text { th, } \\
2018\end{array}$} & 07.00 & Check out & $\begin{array}{l}\text { Pension Am Kirschberg } \\
\text { Dresden }\end{array}$ \\
\hline & & $\begin{array}{l}08.52- \\
09.25\end{array}$ & Dresden - Freiberg & By Train \\
\hline & & $\begin{array}{l}10.00- \\
13.00\end{array}$ & Intercultural Workshop & $\begin{array}{l}\text { Dr. Doris Geburek } \\
\text { Faculty of Economics } \\
\text { TU Bergakademie Freiberg }\end{array}$ \\
\hline & & $\begin{array}{l}13.00- \\
14.00\end{array}$ & Lunch & Mensa \\
\hline & & $\begin{array}{l}14.00- \\
16.30\end{array}$ & $\begin{array}{l}\text { Augmented Reality } \\
\text { Visiting the CAVE - } \\
\text { excursion to Virtual } \\
\text { Reality }\end{array}$ & $\begin{array}{l}\text { D. Vogt - Faculty of Informatics } \\
\text { TU Bergakademie Freiberg }\end{array}$ \\
\hline & & $\begin{array}{l}16.30- \\
17.30\end{array}$ & University Tour & Student assistant IUZ \\
\hline & & $\begin{array}{l}17.31- \\
18.05\end{array}$ & Freiberg - Dresden & By Train \\
\hline
\end{tabular}




\begin{tabular}{|l|l|l|l|l|}
\hline & & $22.15-23.50$ & Dresden - Leipzig & $\begin{array}{l}\text { By Bus } \\
\text { Dresden HBF }\end{array}$ \\
\hline 12 & $\begin{array}{l}\text { Thursda } \\
\text { yApril } \\
19 \text { th, } \\
2018\end{array}$ & $\begin{array}{l}01.00- \\
06.05\end{array}$ & Leipzig - Frankfurt & $\begin{array}{l}\text { By Bus } \\
\text { Leipzig HBF } \\
\text { Verbindung 13 }\end{array}$ \\
\hline & 11.20 & Leaving & $\begin{array}{l}\text { Frankfurt am Main Airport, } \\
\text { Frankfurt, Germany }\end{array}$ \\
\hline 13 & $\begin{array}{l}\text { Saturday } \\
\text { April } \\
21 \text { st, } \\
2018\end{array}$ & 19.15 & Arrival & Adi Sucipto Airport, Yogyakarta \\
\hline
\end{tabular}

Selama proses persiapan yang kurang lebih memakan waktu satu tahun yaitu terhitung maret 2017-Maret 2018 para anggota dengan aktif berpartisipasi dalam rangka mensukseskan program. Salah satu wujud paling sederhana adalah aktifnya percakapan bahasa inggris harian dalam grup WA. Tim penyusun kegiatan mengirip update rancangan aktivitas kegiatan SV melalui grup dan ditanggapi dengan cepat oleh peserta yang lain, diskusi yang membangun pun terjadi. Hal serupa terjadi saat proses penyusunan proposal kegiatan dan penyusunan profil peserta SV. Lebih dari itu, saat tim teknis mengajukan desain spanduk dan kartu peserta, seluruh peserta memberikan masukan guna kesesuain tata bahasa, penggunaan kosakata dan collocation dalam bahasa inggris.

Pelaksanaan SV dengan kegiatan yang sangat padat dan beragam seperti terlihat pada tabel 2 menuntut peserta untuk bertindak cekatan, efisien dan efektif. Kemampuan membaca keterangan di papan-papan petunjuk saat di bandara, bertanya ke pusat informasi apabila ditemukan informasi yang kurang memadai, membeli makanan, memesan tiket bus/kereta api lokal menunjukkan kesiapan peserta sebagai pengguna bahasa inggris sebagai bahasa kedua. Tanya jawab selama di pos imigrasi baik di Singapore, Abu Dhabi dan Jerman dilalui dengan lancar.

Setelah kegiatan SV berhasil dilaksanakan, dilakukan in-depth interview terhadap 5 orang mahasiswa sample guna menemukan pengaruh dari kegiatan SV ditinjau dari pengalaman dan penilaian subjektif peserta. Hasil wawancara terkait perubahan learning attitude yang mempengaruhi goal masa depan mahasiswa peserta, yang menumbuhkan keinginan melanjutkan studi ke negara englishspeaking country karena kesadaran bahwa yang bersangkutan mampu bersaing serta mampu menggunakan bahasa inggris sebagai bahasa pengantar perkuliahan.

\section{SIMPULAN}

Berdasarkan dari hasil pengamatan dan wawancara dapat disimpulkan bahwa kesempatan berinteraksi secara aktif dalam lingkup yang mengharuskan mahasiswa menggunakan bahasa inggris sebagai alat komunikasi utama, meningkatkan kemampuan bahasa inggris mahasiswa tersebut tanpa disadari (unconscious learning) dan membuat mereka semakin termotivasi untuk melanjutkan kuliah mereka di luar negeri. Hasil Pengamatan dibagi dalam tiga tahap yakni persiapan, pelaksanaan dan paska pelaksanaan program SV.

\section{DAFTAR RUJUKAN}

Araminta, L.D.W, Halimi, S.S. 2015. Needs Analysis of Universitas Indonesia's Engineering Students. Indonesian Journal of Applied Linguistics. Vol 5. No $1,11-18$

Gözüyeşi1, E. 2014. An Analysis of Engineering Students' English Language 
Muhfizaturrahmah: Upaya Peningkatan Kemampuan Berbahasa Inggris Melalui Program...

Needs. Procedia- Social and Behavioral. Vol 116. 4182-4186

Yuniarti, N. 2015. Laporan Pelaksanaan Program Internasionalisasi Program Studi Pensisikan Teknik Elektro. Yogyakarta: Fakultas Teknik Universitas Negeri Yogyakarta
Hermaniar, Y, Mubaraq, F.Y. 2016. Integrating Hide and Seek Game on TBL (Task-based Learning) Classroom. Vidya Karya. Vol 31. No 1, 81-90

Cambridge English. 2018. IELTS 13 Academic. United Kingdom : Cambridge University Press 